\title{
SABERES E PRÁTICAS CORPORAIS NA FORMAÇÃO DE PROFESSORES DE EDUCAÇÃO FÍSICA NA MODALIDADE A DISTÂNCIA'
}

\author{
DR. ARI LAZZAROTTI FILHO \\ Faculdade de Educação Física, Universidade Federal \\ de Goiás-UFG (Goiânia - Goiás - Brasil) \\ e-mail: arilazzarotti@gmail.com \\ DRA. ANA MÁRCIA SILVA \\ Faculdade de Educação Física, Universidade Federal \\ de Goiás-UFG (Goiânia - Goiás - Brasil) \\ e-mail: amarciasi@gmail.com

\section{DR. GIOVANI DE LORENZI PIRES} \\ Departamento de Educação Física, Universidade Federal \\ de Santa Catarina (Florianópolis - Santa Catarina - Brasil) \\ e-mail: giovani.pires@ufsc.br
}

\begin{abstract}
RESUMO
O presente texto comunica o resultado de uma investigação que objetivou compreender como é desenvolvido o saber das práticas corporais num curso de licenciatura em Educação Física (EF) na modalidade a distância. A metodologia utilizada foi o estudo de caso e a análise dos dados foi desenvolvida com apoio do software Nvivo 9. I. Como resultado, destaca-se que o saber das práticas corporais marca a perspectiva dos componentes da equipe pedagógica, tanto na sua história de vida como em seus processos de escolarização, além de aparecer como preocupação no desenvolvimento do curso na modalidade a distância. Identifica-se essa preocupação, também, no projeto político pedagógico do curso, mas o processo pedagógico parece estar centrado no saber sobre as práticas corporais desenvolvidas através das mídias digitais.
\end{abstract}

PALAVRAS-CHAVE: Formação de professores; Educação Física; saber das práticas corporais; EaD.

I. Projeto financiado pelo Edital Universal CNPq/2008, processo 477026/2008-7. 
A formação das novas gerações, atividade necessária para a reprodução do campo da EF, pode estar dando sinais de rompimento com uma de suas mais fortes tradições, qual seja, o saber das práticas corporais (SDPC), e tensionando o que até então parecia ser uma condição "sine qua non" de sua existência.

Tal afirmação pode ser ilustrada em dois momentos históricos distintos desse campo: o primeiro foi no ano 1939, com a criação da Escola Nacional de Educação Física e Desporto (ENEFD) vinculada à Universidade do Brasil. Com um caráter eminentemente técnico na formação, teve importância significativa para a constituição do que conhecemos hoje da EF no país (MELO, 2007). O segundo momento ocorreu no ano 2005, com a criação do primeiro curso de formação de professores de EF na modalidade a distância. Esse fato inaugura uma nova fase centrada no processo pedagógico mediado pelas tecnologias de informação e comunicação (TIC). Se no primeiro momento a centralidade da formação estava no SDPC, no segundo, a centralidade pode estar no saber sobre as práticas corporais (SSPC).

De maneira geral, a formação em EF, ao longo dos anos, vem se modificando, mas a especificidade do SDPC sempre compôs os currículos expressando-se em denominações de disciplinas da cultura esportiva (DAOLIO, 1998), como disciplinas teórico-práticas (OLIVEIRA, 1989), como conhecimentos identificadores da área (BRASIL, 2004), como conteúdos do esporte (GONZÁLES, 2004) ou como disciplinas práticas (FIGUEIREDO, 2004). Esses saberes ainda marcam as grades curriculares dos cursos de EF e, em boa parte deles, sua perspectiva técnica e reprodutora do modelo esportivo tem sido fortemente criticada por autores como Oliveira, (1989); Bracht, (1992) e Daolio (1998).

Observa-se também que, a partir da década de 2000, novas perspectivas começam a ser desenvolvidas no trato desses saberes na formação profissional, por autores como: Pires e Neves (2002), González (2004), Nascimento (2004) e Rezer (20 I 0). No entanto, o SDPC compõe a tradição da EF e segundo Figueiredo (2004, p. 99),

[... seria interessante que os alunos conseguissem realizar, associadamente, os dois tipos de aprender: o primeiro, apenas com o objetivo de vivenciar a atividade: o segundo, com o objetivo de dominar o saber-objeto da atividade.

Com base na produção acadêmica do campo é possível afirmar que num determinado momento o SDPC determinou a própria EF brasileira e que, no decorrer dos anos, incorporaram-se outros aspectos que ampliaram suas concepções e práticas, como é o caso do SSPC e o Saber Pedagógico das Práticas Corporais (SPDPC).

O SDPC são saberes técnicos, táticos e estéticos expressos pelo saber fazer, nos quais o ser humano manifesta integralmente sua corporalidade - eixo importante e constituinte da especificidade da EF, e que também se manifesta na formação de professores como forma de autorreprodução e desenvolvimento. Sob essa 
perspectiva, o SDPC pode ser entendido como constituinte do habitus da EF, um modus operandi que atua como princípio unificador, reprodutor e gerador, funcionando segundo suas normas. Trata-se do sentido do jogo que faz com que se faça o que é preciso fazer e constitui-se em certa automatização, um

[...] sistema de disposições inconscientes que constitui o produto da interiorização das estruturas objetivas [...] e das esperanças subjetivas, tende a produzir práticas e, por esta via, carreiras objetivamente ajustadas às estruturas objetivas. (BOURDIEU, 2009, p. 22).

O SSPC é entendido como aquele conhecimento desenvolvido, sistematizado e validado cientificamente sobre uma determinada prática corporal. Foi trazido para a EF de outros campos científicos, em parte, com suas nomenclaturas de origem, tal como fisiologia do exercício ou história da ginástica, constituindo-se como um discurso sobre, conforme denomina Betti (2007), ou como um saber-objeto da atividade, assim identificado por Figueiredo (2004), e ou como o conhecimento sobre o conteúdo, de acordo com Nascimento (2004).

Já o SPDPC identifica o saber pedagógico desenvolvido "a partir das" e "sobre as" práticas corporais, isto é, o saber ensinar oriundo da capacidade de transformação, dos conhecimentos historicamente produzidos e socialmente reconhecidos como necessários e válidos em conhecimentos didático-pedagógicos. Tratando-se de cursos de licenciatura essa é sem dúvida uma dimensão indispensável, até mesmo identificadora da formação de professores de Educação Física, seja na modalidade presencial ou a distância, porém nesse trabalho não será objeto central de análise.

$\mathrm{Na} \mathrm{EaD}$, faz-se necessário investigar como o SDPC vem sendo desenvolvido, visto que essa nova formação incorpora a mediação por computadores e em espaço virtual, assumindo contornos diferenciados daquilo que tradicionalmente vinha sendo realizado no campo, mediação essa que pode estar acirrando as contradições e ambiguidades do campo no que tange a sua tradição com o SDPC.

Como os cursos nessa modalidade são recentes, necessitam, além do tempo para se consolidarem e criarem experiências próprias, pesquisas que possam analisar seu desenvolvimento. E é com esse intuito que se apresenta essa comunicação, resultado de uma pesquisa que investigou como o curso de Licenciatura em EF na modalidade a distância da UFG, principalmente na perspectiva de seus agentes, componentes institucionais e equipe pedagógica, desenvolve o SDPC no processo de formaçã̃o dos novos professores.

\section{METODOLOGIA}

A pesquisa em questão pode ser caracterizada como um estudo de caso (ANDRÉ, 2005) e teve como corpus empírico de análise: a) entrevista semiestruturada 
com dezesseis membros da equipe pedagógica, sendo que, dentre esses, havia oito professores autores/formadores, quatro orientadores acadêmicos e quatro tutores presenciais; b) Projeto Político Pedagógico do Curso de Formação de Professores (PPP); c) diagnóstico dos nove Polos, realizado através de visitas e de entrevistas via telefone; d) material didático (MD) produzido por quatro disciplinas já concluídas e que continham conteúdos do SDPC, sendo elas: Pesquisa e ensino em ginástica escolar (PEGE); Pesquisa e ensino em jogos e brincadeiras (PEJB); Pesquisa e ensino em natação (PEN); e Pesquisa e ensino em atletismo (PEA).

A análise dos dados foi realizada com o apoio do software Nvivo 9.1, que proporcionou a construção de um sistema de codificação aglutinando aspectos que expressavam o SDPC como compreensões, impressões, valorações dos sujeitos envolvidos, os conceitos, expressões e formas de materialização, definidos como codificação de primeira ordem. Depois dessa etapa, criou-se um sistema de codificação, estabelecendo relações de proximidade com temas secundários, construindo uma codificação de segunda ordem com temas aglutinadores, tais como: a presença das práticas corporais na história de vida dos componentes da equipe pedagógica; a sua manutenção das práticas na atualidade; a sua integração no desenvolvimento do curso na modalidade a distância; a dinâmica de trabalho do curso; as valorações positivas do curso a distância; e os principais problemas na sua efetivação.

Com essa mesma sistemática, os documentos foram codificados, tornando possível identificar a frequência com que apareceram os códigos e sua relevância e importância para a compreensão do problema de pesquisa. Posteriormente, os códigos foram analisados para atribuir significados, criando inferências e análises que sustentaram as conclusões parciais.

A coleta de dados foi realizada no período compreendido entre outubro de 2009 e abril de 201 I, e a seleção dos entrevistados seguiu os seguintes critérios: a) professor autor/formador: todos que já trabalharam no curso no período; b) orientador acadêmico e tutor presencial: seleção aleatória. Também vale salientar que o processo de codificação usado para se reportar ao material analisado segue uma sequência de letras e números. As letras expressam as iniciais do documento de origem: PPP - Projeto Político Pedagógico; E - entrevista; identificam os entrevistados, sendo PF - Professor autor/formador; OA - Orientador Acadêmico; TP Tutor Presencial. Os sujeitos da pesquisa, em número de 16, foram denominados, nessa pesquisa, como SA, SB até SQ; os documentos foram nomeados como MD Material Didático, seguido das iniciais da disciplina e de um número que identifica a codificação no referido documento. 


\section{APRESENTAÇÃO E DISCUSSÃO DOS DADOS}

Os saberes oriundos da experiência com as práticas corporais têm sido tema de estudos no campo da EF, os quais buscam compreender como tais saberes influenciam, determinam, e integram a formação e intervenção profissional, atuando na reprodução do campo. Acredita-se que os professores, como sujeitos sociais, já estão envoltos por esses saberes no decorrer das suas histórias, constituindo-se como disposições duráveis (BOURDIEU, 2004). Tais disposições interferem em suas práticas pedagógicas mais do que se acreditava, principalmente por estarem já imersos em média há 15 anos na cultura escolar, ao longo da Educação Básica e nas experiências fora da escola com o esporte e o lazer.

Ao analisar as experiências anteriores dos componentes da equipe pedagógica do curso em questão, foi possível perceber, nos seus depoimentos, algumas marcas do SDPC e que os mesmos advêm de diferentes fontes, como a EF escolar, as escolinhas de esportes e jogos escolares, os clubes esportivos e recreativos, as academias de ginástica e escolas de dança. Observa-se, então, que o SDPC constituiu sua cultura de origem, principalmente, via instituição esportiva, influenciando sua opção profissional e suas concepções de formação de professores.

Perguntados se as experiências anteriores com as práticas corporais determinaram a escolha pelo curso de EF, a maioria dos entrevistados confirmou com veemência essa influência, tal como exemplificado nas falas a seguir: "Pratiquei handebol desde os dez anos e joguei no time da cidade nos últimos quatro anos, foi quando eu defini mesmo que queria fazer o curso de EF". (ETPSA2); "Acabou me motivando" (EPFSQ3); "Sim, com certeza!". A centralidade das experiências anteriores manifesta-se pelo esporte específico, geralmente através de uma especialização ou também pela diversificação com as experiências em várias práticas corporais. A marca da especialização pode ser observada nos seguintes depoimentos: "(...) fui ginasta durante grande parte da minha vida, dos meus oito aos meus 28 anos de idade. Eu fui ginasta de competição... (...)” (EPFSL I); “(...) eu fui atleta de handebol, durante vinte anos (...)" (EPFSHI); "olha, foi (...) eu sempre participei assim (...) eu tenho muitas medalhas, troféus (...) eu corria maratona, daí então eu sempre gostei dessas práticas". (EPFSM2).

A experiência com várias práticas corporais também pode ser identificada na fala que segue: "(...) na minha vida desde criança as práticas corporais sempre estiveram presentes. Fiz ginástica por muito tempo e participei de varias outras práticas. Fiz escolinha de vôlei, de futsal, de basquete (...)" (EOASN2).

Identificou-se, em duas entrevistas, que há disposições positivas e negativas para a escolha do curso. Na positiva, percebe-se o quanto o esporte contribuiu 
para a formação do sujeito envolvido: "Falar da minha história, sem falar de esporte, não tem história" (EPFSQ3 I). Já como valoração negativa, o processo de exclusão do próprio esporte e de outras práticas corporais acabou sendo o estopim para a escolha da EF, como pode ser notado no seguinte depoimento: "(...) como eu era gordinha e meio desajeitada, eu era sempre excluída então, parece que eu fiz um pouco por vingança o curso de EF". (IESHM2).

Foi possível identificar, em outra entrevista, que o processo de escolarização e, mais especificamente, o professor, teria sido o grande motivador da opção pelo curso. No entanto, vale destacar que essa referência, o professor, não foi o motivador para a maioria dos entrevistados. $\bigcirc$ que se observou foi que as figuras de projeção de um vir a ser profissional são oriundas do modelo esportivo, como o atleta, o treinador ou o instrutor. Esse mesmo movimento aparece nas predisposições dos estudantes do mesmo curso, conforme Cruvinel, Lazzarotti Filho e Silva (20 I I) e em pesquisa realizada por Figueiredo (2004), sobre a influência de tais saberes na formação de professores. A última autora citada conclui que há uma sobreposição do saber da experiência em relação ao saber da formação, e que os estudantes saem sem ter mudado a concepção de EF que tinham ao iniciar o curso.

Considerando que a experiência com as práticas corporais foi determinante para a escolha do curso de EF, não se identifica, porém, a manutenção dessas práticas no cotidiano da maioria dos integrantes da equipe pedagógica. Questionados se as práticas corporais são realizadas regularmente, identificam-se duas situações: na primeira, a maioria dos professores autores e formadores respondeu que não mantém essas práticas de forma regular e que atualmente elas seriam objetos/temas de pesquisa e ensino e pouco incorporadas ao cotidiano. Já um segundo grupo, formado preponderantemente de orientadores acadêmicos e tutores presenciais, mais jovens, informa que mantém ao menos uma prática corporal regular em seu cotidiano ou que as desenvolve como SDPC, com os seus estudantes, no próprio ato de ensinar, como se pode verificar nas falas que seguem: "Agora eu quero voltar, vou entrar em um projeto de atletismo na prefeitura de Anápolis e eu vou trabalhar com um polo do centro-oeste que vai ter atletismo aí eu quero voltar a correr por lá" (EOASCI). "Eu só nado (...) porque dou aula de natação, a natação eu nunca parei". (EOASC2). "Nesse último mês já diminui, mas a prática corporal que eu tenho hoje são as aulas de EF que eu ministro. Então, em todas elas eu acabo me envolvendo com o alunado, e acabo participando junto. Corrida, dança, ginástica (...), todos esses conteúdos a gente acaba vivenciando junto com eles, mas a gente sabe que não é uma prática cotidiana (...)". (EOASE I).

Dessa forma, constatou-se que na equipe pedagógica há dois grupos de professores com perfis diferenciados, tal como na tipologia de Tardif (2008), que 
pode ser percebida em função dos momentos e fases da profissão docente: o grupo dos professores autores/formadores, com idade entre 35 e 60 anos e dedicação exclusiva no ensino superior, que não realizam práticas corporais cotidianamente; e o grupo dos orientadores acadêmicos e tutores presenciais, em sua maioria professores no ensino médio e fundamental, com idade entre 21 e 30 anos, para os quais as práticas corporais constituem parte de sua rotina, seja junto com os seus estudantes, no cotidiano da escola, seja como prática regular em outros ambientes.

$\mathrm{Na}$ análise do PPP, o SDPC aparece como um desafio que o curso terá que vencer na constituição da especificidade do campo da EF. Em vários trechos do documento identifica-se menção ao tema:

Para a Faculdade de EF da UFG, a formação da docência possui uma natureza própria, que advém da inter-relação entre o ensino, a pesquisa e a extensão, e está plenamente vinculada ao saber e ao fazer, à teoria e à prática, à pesquisa e à intervenção educativa nas diferentes tarefas e dimensões do homem, mediada pela corporalidade humana, em seu sentido pessoal e coletivo social, ora denominada EF. (PPPI)

Em outro trecho, percebe-se a preocupação com o reconhecimento da história do campo:

Para apontar a dinâmica das atividades a distância e presenciais, num curso de Licenciatura em Educação a Distância, é fundamental reconhecer a histórica valorização da dimensão prática no campo da EF brasileira, ou seja, a importância atribuída ao saber fazer. (PPPI6)

O documento considera as manifestações culturais sistematizadas nas práticas corporais como componentes de sua identidade, as quais seriam ampliadas com a entrada no ciberespaço:

Talvez aqui nos deparemos com um problema da especificidade desse campo de conhecimento, que tem nas práticas corporais a sua constituição de identidade. A formação de professores na modalidade de ensino a distância, portanto, mediada por tecnologias de comunicação e informação, não deve negar essa dimensão da formação docente, ou seja, a prática, e ao mesmo tempo deverá dialogar com a cultura sobre o corpo que vem assumindo outros contornos no ciberespaço. (PPPI7)

Quando questionados sobre o tema, todos os integrantes da equipe pedagógica afirmaram que os componentes do SDPC são importantes na formação de professores de EF, porém, para alguns, não são fundamentais, conforme se constata nos depoimentos a seguir: "Essencial! Mesmo que seja uma vivência que eu nunca vou conseguir atingir todos os esportes, sempre vai existir o que eu gosto e o que eu não gosto, mas eu tenho que aprender". (EOASC2). "(...) não tem como você falar sem ter esse conhecimento um pouco mais aprofundado, então por isso eu 
acredito que é importante essa... experimentação, essa vivência." (EOASBI). "Eu acho importante no sentido do conhecimento, mas não da execução do movimento, execução perfeita da técnica, mas no sentido da vivência, talvez de ter experimentado algo, de ter sentido na pele como que é essa execução, mas não no sentido de saber fazer, de ter que saber fazer." (EOASDI). "Agora para a EF essas aulas práticas são totalmente importantes, pois é a essência da EF enquanto conteúdo (...)" (EOASEI).

Nos materiais didáticos das quatro disciplinas analisadas, é possível verificar a preocupação com o SDPC, porém, a ênfase está no saber sobre as práticas corporais (SSPC), com o uso de vídeos, imagens ou nas descrições do corpo ou partes do corpo, do corpo em movimento, de técnicas esportivas e das sequências de movimento. Destacam-se os seguintes textos:

A Marcha atlética é uma progressão de passos executados de tal modo que o atleta mantenha um contato contínuo com o solo, não podendo ocorrer a olho nu, a perda do contato com o solo. A perna que avança deve estar reta, ou seja, não flexionada no joelho, desde o primeiro contato com o solo, até a posição ereta vertical (...) (MDPEAII).

O movimento para a inspiração é através da rotação lateral do tronco e de uma pequena rotação de pescoço. A inspiração deve ser realizada pela boca e na onda de proa, mantendo a boca o mais próximo possível da água, e acontece no momento em que um braço estiver na fase de apoio e o outro na finalização da braçada.A respiração é classificada de acordo com o número de braçadas (2XI, 3XI ou bilateral, 4XI ...). (MDPENI5).

Nessa modalidade de curso, a ênfase do material didático recai sobre a descrição do corpo e do movimento, enquanto na modalidade presencial esse conhecimento geralmente é desenvolvido através da movimentação em si. $\bigcirc$ desenvolvimento do SSPC utiliza-se dos acúmulos históricos da Educação Física e de áreas afins, como aqueles produzidos pela EaD, dentre os quais, talvez, o mais significativo seja a integração das mídias. ${ }^{2}$

No que se refere às mídias, o PPP afirma que objetiva não somente integrá-las no processo, considerando seus agentes como receptores, mas também utilizá-las em processos criativos, como se pode comprovar no texto a seguir:

Outra importante característica do ambiente de aprendizagem está relacionada com a possibilidade de fazer com que o professor-aluno, ao longo do curso, possa criar um produto em suporte ou meio de comunicação não exclusivamente textual, como, por exemplo, animação, simulação ou hipertexto. (PPP2)

2. Na história da EaD é possível identificar a caracterização dessa modalidade pela própria integração das mídias: num primeiro momento, caracterizava-se pelas apostilas que chegavam até os estudantes pelo correio; num segundo momento, pelas ondas do rádio e da televisão; e num terceiro momento, mediada pelas tecnologias de rede (NIPPER, 1989). 
Pode-se dizer que a integração das mídias foi constantemente mobilizada no desenvolvimento das disciplinas analisadas. A imagem, aliada à descrição, foi a mais utilizada para representar ou demonstrar partes do corpo, do movimento ou sequências de movimentos. As imagens foram digitalizadas e englobam fotografias ou ilustrações, recurso recorrente nos materiais didáticos analisados. Identificou-se também a produção de vídeos pelos professores, porém, em menor proporção, com um uso frequente de recursos disponíveis na rede mundial de computador, sobretudo do youtube.

A produção textual, no modelo didático/acadêmico, foi o recurso mais utilizado para delimitar o conteúdo a ser desenvolvido. $\bigcirc$ material didático das quatro disciplinas analisadas tem como característica a exposição de conceitos, de aspectos históricos e, principalmente, possuem como característica central a descrição anteriormente mencionada.

Para o desenvolvimento do processo pedagógico é utilizada a plataforma Moodle, software de código aberto desenvolvido colaborativamente e disponibilizado gratuitamente para instalação e customização. Esse ambiente, mais conhecido como Ambiente Virtual de Aprendizagem-AVA é anunciado no PPP do curso, apresentando os recursos e as ferramentas necessárias para o processo. (PPP7)

O fórum, ferramenta assíncrona disponível no AVA, é o recurso mais utilizado no processo ensino-aprendizagem e para a comunicação entre a equipe pedagógica, e dela com os estudantes. Com menor referência, identificou-se o uso de webconferência, vídeo-aula, animações e indicações de sites, além da integração das mídias digitais no processo pedagógico.

Já a produção audiovisual foi uma prática identificada em duas disciplinas: em uma, há uma produção de um cd multimídia, pela própria equipe da disciplina, com centralidade no movimento ginástico, demonstrando determinadas técnicas; e na outra, a tarefa foi desenvolvida pelos próprios estudantes, demonstrando, segundo a professora formadora, aspectos da cidade educadora.

A estratégia de utilização de vídeo como forma de apreender técnicas corporais ou práticas específicas foi abordada nas entrevistas, em falas como as que seguem: "(...) a gente usou alguns vídeos como exemplo, que já tinham imagens do formato de como nadar, de onde, de como o braço entra, o que o braço faz, assim, de exemplificações, de posições (...)". (EPFSQI2). "A própria produção do texto, visando esse aluno à distância. Então um texto que traz mais imagens a partir do uso de metáforas é (...) a própria proposição de trabalhar com mídias, com novas mídias, no caso com imagens, com edição de imagens, com montagem de pequenos documentários (...)" (EPFSO2) 
Parece que as mídias digitais se tornaram centrais para o desenvolvimento do curso na modalidade a distância. E segundo as palavras de uma professora formadora, a qual também desempenha a função de coordenadora do curso, podem diminuir a distância entre o SDPC e o SSPC: "Eu acho que, quando a gente souber usar todas essas tecnologias, aprender a comunicar de outras formas, eu acho que até essas práticas corporais, (...) é possível encontrar uma forma de ensiná-las mais a distancia, sem tanta vivência prática [...] (EPFSJI6). Percebe-se uma preocupação com o SSPC marcada, especialmente, pela apreensão "cognitiva". Tal afirmação pode ser observada no material didático, digitalizado e disponibilizado aos estudantes na plataforma, o qual alia a descrição à demonstração de imagens.

O processo aproxima-se da lógica de apreender cognitivamente o SDPC como um SSPC, sobretudo a partir das mídias digitais. Nos poucos encontros presenciais realizados, o SDPC são experienciados pelos estudantes, e quando os componentes da equipe pedagógica foram questionados sobre o tempo dedicado ao SDPC e se consideravam suficiente este tempo para o processo de formação de novos professores, a maioria afirmou que, em relação ao curso presencial e, principalmente, em relação à sua experiência como estudante, o tempo dedicado a essas práticas é muito menor e os estudantes podem vir a ter problemas quando de sua intervenção profissional. No entanto, afirmam que a aprendizagem do SSPC, no âmbito "cognitivo", acaba sendo maior, visto que uma das características do curso na modalidade a distância é a sistematização de todo o conteúdo da disciplina, o que facilitaria sua apreensão por parte do alunado.

A maioria dos componentes da equipe pedagógica aponta como valoração positiva o desenvolvimento das capacidades cognitivas dos estudantes, por exemplo, a exercitação da linguagem culta e a capacidade de organizar, sistematizar e expressar-se adequadamente na forma escrita: "Eu vejo muitas [vantagens], mas, uma das maiores qualidades do curso é... preparar o aluno pra ser.... para pesquisa, para discussão, para debate (...)" (EOASDI). "Desperta muito mais o aluno pela busca, pelo conhecimento, pela pesquisa e o aluno que não desperta pra isso ele fica pra trás, e isso aí é um ponto positivo (...)" (ETPSAI). "(...) eles fazem mais leitura que o pessoal da presencial (...) indiscutivelmente." (EPFSLI). "É a questão da escrita (...)" (EPFSOI).

Em relação ao PPP do curso, é possível inferir que nele se encontram marcas da valoração do SDPC em disciplinas constituintes do universo das Práticas Corporais que expressam a tradição desse campo e são assim denominadas: Pesquisa e Ensino em Natação; Pesquisa e Ensino em Atletismo; Pesquisa e Ensino em Voleibol; Pesquisa e Ensino em Basquetebol; Pesquisa e Ensino em Futebol; Pesquisa e Ensino em Handebol; Fundamentos Sócio-Culturais das Lutas na EF; Pesquisa e Ensino em Jogos e Brincadeiras; Pesquisa e Ensino em Dança, Pesquisa e Ensino em Ginástica. 
Tais títulos buscam ampliar o entendimento e a tradicional centralidade do currículo no SDPC, visto que todas são intituladas de "ensino e pesquisa em...". Ainda que mantenham uma referência nas práticas corporais, incluem o enfoque no ensino e na pesquisa ao tratar o futebol, o vôlei, a dança, a ginástica, entre outros. Tais denominações parecem buscar representar um movimento do campo destinado a fazer ver e fazer valer uma maneira de ver o campo da EF (BOURDIEU, 2004). Nas ementas dessas disciplinas identifica-se uma unidade apresentando um componente do SDPC expresso pelo texto: "Conhecimento teórico-prático dos fundamentos técnicos e regras básicas do (...)" (PPPE7).

Para o seu desenvolvimento, o PPP do curso apresenta as condições de infraestrutura para os polos com três laboratórios pedagógicos: Laboratórios de práticas esportivas, Laboratório de linguagem e expressão e Laboratório de atividade física e saúde, para os quais é feita uma descrição de finalidade, de materiais e de equipamentos necessários.

O diagnóstico dos nove polos do curso identificou, porém, que não existem tais laboratórios e não estão previstas suas construções nem mesmo no médio ou no longo prazo. Quando questionados sobre os laboratórios, os coordenadores dos polos apontam para os convênios celebrados com academias de ginástica, clubes esportivos, ginásios municipais e estaduais, escolas públicas, entre outros, cujo acesso ou uso sistemático, pelos estudantes, não ficou evidenciado.

Para o desenvolvimento das disciplinas designadas como teórico-práticas, o PPP define que 30\% da carga horária dessas disciplinas devem ser desenvolvidas de forma presencial e que são previstos quatro encontros presenciais. A dinâmica do trabalho, identificada nas entrevistas com os componentes da equipe pedagógica, parece ser organizada em uma lógica diferente da anunciada no PPP do curso. Como não existe, nos polos, a infraestrutura necessária, todos os estudantes e tutores presenciais são deslocados, ao menos uma vez no bimestre, para a sede da FEF/ UFG, unidade acadêmica que apresenta infraestrutura, materiais e equipamentos que possibilitam as experiências com as práticas corporais.

Durante as entrevistas, identificou-se que os encontros presenciais acontecem, de modo geral, de duas maneiras: nos polos, onde os orientadores acadêmicos, juntamente com os tutores presenciais, desenvolvem atividades com os estudantes, sendo que esses encontros são, geralmente, de cunho introdutório ou avaliativo; ou então no decorrer do bimestre, quando os estudantes e tutores presenciais são deslocados para a sede da FEF/UFG. Com relação a esse último tipo de encontro, a dinâmica do trabalho, quase que na maioria das disciplinas, acontece sob a forma de circuitos em que os estudantes passam por estações e experimentam determinadas práticas, conforme atestam os depoimentos que seguem: "[...] foi um encontro 
presencial que vieram todos os polos simultaneamente para Goiânia, nós fizemos várias estações (...)." (EPFSH3). "No terceiro encontro presencial vieram todos os polos para Goiânia. Foi um encontro coletivo e aí foi um encontro eminentemente prático, só teve uma hora de aula teórica que aí foi com a professora formadora, uma hora e meia, mais ou menos, e depois nós passamos o resto do dia todo em aulas práticas, e aí foi a professora formadora que ministrou, que conduziu essas atividades e nós orientadores acompanhamos, auxiliamos no decorrer do dia." (EOASNI). "(...) agora no presencial de atletismo, vivenciaram o arremesso, o salto, a corrida na pista lá na FEF." (ETPSPI). Tais encontros aconteceram nas sextas-feiras, à noite, e aos sábados, nos períodos matutino e vespertino.

Essa dinâmica de trabalho da EaD acaba também tensionando a própria tradição dos agentes do curso que, como identificado anteriormente, são marcados pelas experiências do modelo presencial, e que nesse momento se veem compelidos a incorporar as tecnologias de comunicação e informação no seu cotidiano. Por serem novas, essas tecnologias tensionam o próprio modus operandi didático-pedagógico, criando certo desconforto e exigindo novos saberes e novas práticas.

\section{CONSIDERAÇÕES FINAIS}

O referido estudo identificou a objetivação, seja através da percepção dos sujeitos envolvidos, seja nos planos de ensino, no PPP e no material didático de disciplinas teórico-práticas para compreender o processo de formação profissional, parte importante da autorreprodução do campo da Educação Física. No caso de cursos na modalidade a distância, estes constituem um contexto novo que acirra e tensiona suas ambiguidades, colocando em xeque a tradição do SDPC. Traz à tona, também, novas funções pedagógicas, ao substituir o professor isolado em sua disciplina por um coletivo de professores e profissionais integrados pelas mídias digitais no processo pedagógico, exigindo, por isso, novos saberes e novas práticas por parte dos agentes formadores em EF.

Pode-se afirmar, na análise do curso em questão, que o SDPC é considerado importante, necessário e parte constituinte do processo de formação de professores de EF. Esse saber é desenvolvido nos encontros presenciais que possibilitam vivências, mas segundo a percepção dos componentes da equipe pedagógica, essas vivências são inferiores às experiências por eles realizadas, o que pode trazer dificuldade quando acionadas por esses futuros profissionais no cotidiano escolar. O SSPC, diferentemente, é considerado um dos pontos positivos da formação a distância, sobretudo no que se refere à incorporação das mídias digitais, com a descrição e visualização das partes do corpo e de técnicas corporais. O SDPC aparece como preocupação do curso na nova modalidade, e é expresso tanto nos documentos 
como nas entrevistas realizadas com os componentes da equipe pedagógica, sendo considerado importante para a formação dos professores de EF. No entanto, o curso desenvolve-se com fortes tendências para a valorização do SSPC e, sendo assim, o conhecimento teórico sistematizado ocupa a centralidade dessas disciplinas e, talvez, de todo o curso.

Para finalizar, recomenda-se um maior investimento no desenvolvimento das disciplinas das práticas corporais nos cursos de formação de professores, especialmente na modalidade a distancia. Também há necessidade de mais investigações sobre seus procedimentos didático-metodológicos na formação em nível superior, com a finalidade de trazer à tona as boas práticas. As críticas ao modelo esportivizado de currículo foram anunciadas nas décadas de 1980 e 1990, mas sua materialização em propostas superadoras nos novos currículos pouco avançou nesse período, inclusive, porque essas disciplinas acabaram assumindo menor valor e prestígio nos cursos, sendo desenvolvidas, em grande medida, por professores substitutos, como bem salienta Souza (2007). No entanto, com os novos cursos de EF nessa nova modalidade, parece que há novos tensionamentos sobre o SDPC, exigindo dos agentes e instituições do campo novos investimentos e práticas superadoras.

\section{Corporal Knowledge and Practices in the Formation of Physical Education Teachers in Distance Learning Modality}

ABSTRACT: The present text aims to communicate the result of an investigation whose purpose was to comprehend how corporal practices knowledge (CPK) is developed in a Physical Education (PE) teacher's formation course in distance learning modality. The methodology used was a case study and the data analysis was developed with the Nvivo 9. I software assistance. As a result, one highlights that corporal practice knowledge marks the pedagogical group's components perspective, specially their life story and also their schooling processes, besides being a concern in the distance learning education course development. This concern is also identified in the course's political pedagogical project, but the pedagogical process seems to be centered on the knowledge about body practices developed as through the digital media. KEY-WORDS: Teacher formation; physical education; corporal practices knowledge; distance learning education

\section{Conocimiento y prácticas corporales en la formación de profesores de educación física en el modo de distancia}

RESUMEN: El presente texto comunica el resultado de una investigación que objetivó comprender cómo se desarrolla el saber de las prácticas corporales en un curso de licenciatura em Educación Física (EF) en la modalidad a distancia. La metodología utilizada fue el estudio de casos y el análisis de datos fue desarrollado con el apoyo del software Nvivo 9.1. Como 
resultado de ello, se hace hincapié en que el conocimiento del cuerpo marca el punto de vista práctico de los componentes del personal docente, tanto en su historia de vida, especialmente en sus procesos de escolarización, y aparecen como una preocupación en el desarrollo del curso en modalidad a distancia. Se identifica esta preocupación, también en el proyecto político pedagógico del curso, pero el proceso pedagógico de aprendizaje parece estar centrado en el saber sobre las prácticas corporales desarrolladas a través de los medios digitales.

PALABRAS CLAVE: Formación de profesores; educación física; saber de las prácticas; corporales

\section{REFERÊNCIAS}

ANDRÉ, M. E. D. A. Estudo de caso em Pesquisa e avaliação educacional. Brasília: Liber Livro, 2005.

BETTI, M. Educação física e cultura corporal de movimento: uma perspectiva fenomenológica e semiótica. Revista da Educação Física/UEM, Maringá, v. I8, p. 207-2 17, 2007.

BRACHT, V. Educação Física e aprendizagem social. Porto Alegre: Magister, 1992.

BRASIL. Conselho Nacional de Educação (CNE). Câmara de Educação Superior (CES). Resolução n. 07, de 3 I de março de 2004: estabelece as diretrizes curriculares para os cursos de bacharelado. Brasília, 2004.

BOURDIEU, P. Os usos sociais da ciência: por uma sociologia clínica do campo científico. Trad. Denice B. Catani. São Paulo: Ed. da Unesp, 2004.

BOURDIEU, Pierre. O poder simbólico. Trad. Fernando Tomaz. Rio de Janeiro: Bertrand Brasil, 2009.

DAOLIO, J. Fenômeno social esporte na formação profissional em Educação Física. Revista da Educação Física/UEM, Maringá, v. 9 n. I , p. I I - | | 5, 1998.

CRUVINEL, F.; LAZZAROTTI FILHO, A.; SILVA, A. M. Perfil dos estudantes da licenciatura em Educação Física da Universidade Federal de Goiás na modalidade a distância. Lecturas Educación Física y Deportes, Buenos Aires, v. 16, n. 156, p. I-9, fev. 201 I.

FIGUEIREDO, Z. C. C. Formação docente em Educação Física: experiências sociais e relação com o saber. Movimento, Porto Alegre, v. I0, n. I, p. 89- I I2, jan./abr. 2004.

GONZÁlEZ, F. J. O estudo do esporte na formação superior em Educação Física: construindo novos horizontes. Movimento, Porto Alegre, v. 10, n. I, p. 21 3-229, jan./abr. 2004.

MELO, V. A. A Educação Física e o Estado Novo ( 1937 - 1945): a Escola Nacional de Educação Física e Desportos. Lecturas Educación Física y Deportes, Buenos Aires, v. I I, n. I I 5 p. I , 2007.

NASCIMENTO, J. V. Metodologias de ensino dos esportes: avanços teóricos e implicações práticas. Revista Portuguesa de Ciências do Desporto, Porto, v. 4, n. 2, 2004.

NIPPER, S. Third generation distance learning and computer conferencing. In: MASON, R.; 
KAYE, A. (Ed.). Mindweave: communication, computers and distance education. Oxford: Permagon, 1989. p. 63-73.

OLIVEIRA, A. A. B. Análise crítica do currículo das disciplinas práticas do curso de educação física da universidade estadual de Maringá. Revista da Educação Física/UEM, Maringá, v. 0 , n. I, 1989.

PIRES, G. L.; NEVES, A. O trato com o conhecimento do esporte na formação em educação física: possibilidades para sua transformação didática. In: KUNZ, E. (Org.). Didática da Educação Física 2. ljuí: Ed. da Unijuí, 2002. p. 53-95.

REZER, R. Reflexões didático-pedagógicas acerca do ensino do esporte no processo de formação de professores de Educação Física. Movimento, Porto Alegre, v. 16, n. I, p. 27 I292, jan./mar. 2010.

TARDIF, M. Saberes docentes e formação de professores. 9. ed. Petrópolis: Vozes, 2008.

SOUZA, N. P. de. O ensino das disciplinas esportivas coletivas nos cursos de licenciatura em Goiás: um estudo descritivo. 2007. 200 f. Tese (Doutorado em Educação Física) - Faculdade de Educação Física, Campinas, 2007.

Recebido em: I I nov. 20 I I

Aprovado em: 14 maio 2012

Endereço para correspondência

Ari Lazzarotti Filho

Universidade Federal de Goiás, Faculdade de Educação Física.

Campus II Samambaia, Bairro Samambaia, CEP: 7400I-970, Goiânia-GO, Brasil.

E-mail: arilazzarotti@gmail.com 